\author{
José Beleña \\ Ivan Petersen \\ Raúl Cabeza \\ Mónica Núñez \\ Alfonso Vidal
}

\section{Migraine headache: a rare complication after cervicothoracic block}

Received: 16 May 2006

Accepted in revised form: 26 June 2006

Published online: 25 October 2006
A 41-year-old woman diagnosed with post-injury complex regional pain syndrome (CRPS) type II involving her left hand came to the Pain Clinic. The rest of her medical history was unremarkable. A left cervicothoracic sympathetic block according to the classic method, using $8 \mathrm{ml}$ of $0.375 \%$ ropivacaine, was performed without incident. The patient developed a left side Horner's syndrome and other signs of sympathetic blockade in her left arm. Thirty minutes following the block, she developed sudden blurry vision added to speech disturbances and 30 min later she reported an intensive and progressive left frontal headache accompanied by nausea and phonophobia. The patient did not have a history of migraine headache or any other chronic headache condition. She received sumatriptan succinate, with good response. Twenty-four hours later she came to the ER reporting the same intense left hemicranial headache with aura. During the following 3 months her episodic left headaches occurred once every couple of weeks. The neurologist reported a normal neurologic examination and diagnosed the headache as a limited migraine headache with aura and her episodic headache resolved completely.

We only found one other report describing this phenomenon in a patient, with a previous history of meningitis [1]. But how did the cervi- cothoracic block trigger the headache in a patient without neurological or vascular disorders? Extracranial blood flow is increased by $50 \%$ during migraine headache, compared to normal subjects, and there is some evidence that this contributes to pain in some migraine sufferers [2]. This increase may result from alterations in sympathetic tone. Cervicothoracic block increases intracranial blood flow [3], and probably the sympathetic blockade produced by the technique may precipitate the migraine headache [4]. Other possible explanations include coincidence and factitious or psychogenic causes.

Finally, we cannot conclude on the pathogenesis of migraine, but vascular and neurologic mechanisms are involved in this complex disorder.

J. Beleña (凶), R. Cabeza, M. Núñez Anesthesiology and Critical Care, Ramón y Cajal Hospital, Madrid, Spain

e-mail: josemariabelena@yahoo.es

I. Petersen Department of Anesthesiology, Odense University Hospital, Odense, Denmark

A. Vidal

Department of Anesthesiology, Capio Hospital Sur, Madrid, Spain 


\section{References}

1. Lehmann LJ, Warfield CA, Bajwa ZH (1996) Migraine headache following stellate ganglion block for reflex sympathetic dystrophy. Headache 36:335-337

2. Drummond PD, Lance JW (1983)

Extracranial vascular changes and the source of pain in migraine headache. Ann Neurol 13:32-37
3. Umeyama T, Kugimiya T, Ogawa T et al (1995) Changes in cerebral blood flow estimated after stellate ganglion block by single photon emission computed tomography. J Auton Nerv Syst 50:339-346
4. Drummond PD (1991) Effects of body heating and mental arithmetic on facial sweating and blood flow in unilateral migraine headache. Psychophysiology 28:172-176 